\title{
Evaluation of microbial diversity of different soil layers at a contaminated diesel site
}

\author{
Mphekgo P. Maila, P. Randima, K. Surridge, K. Drønen, Thomas E. Cloete
}

\section{Introduction}

The effect of hydrocarbon contamination on soil microbial communities has been extensively studied, for example by Atlas et al. (1991), Wunsche et al. (1995), Lindstrom et al. (1999), MacNaughton et al. (1999), Stephen et al. (1999), Juck et al. (2000) and Bundy et al. (2002). However, these studies used mainly topsoil to investigate the effect of hydrocarbons on soil microbial communities. Information about the microbial diversity of different soil layers at the given sites is lacking. Because oil contamination normally penetrates deeper than the top layer, it is important to understand the distribution of degrading populations with soil depth and how the distribution patterns influence the efficiency of biodegradation.

The subsurface soil environment, though devoid of sufficient nutrients, oxygen and other factors, harbours an array of soil microorganisms that play an important role in decomposition and the recycling of nutrients (Krumholz, 1998). It is widely presumed that the number of heterotrophic bacteria changes with depth. This can be attributed to spatial and resource factors that can influence the microbial diversity of the soil (Zhou et al., 2002). The shallow subsurface microbiota appears to be predominantly prokaryotic and specially adapted for growth and survival in nutrient-poor conditions; it includes strains that can function over a wide range of nutrient concentrations; and may sometimes exert a significant effect on groundwater chemistry (Ghiorse and Balkwill, 1983; Balkwill and Ghiorse, 1985; Bone and Balkwill, 1988; Ghiorse and Wilson, 1988; Balkwill et al., 1989).

The availability of hydrocarbons in the vadose zone can alter the diversity of the heterotrophic community owing to an increase in the carbon substrate. According to Atlas (1981) and Leahy and Colwell (1990), the number and relative abundance of hydrocarbon-degrading bacteria in the bacterial communities increases significantly in the presence of readily available hydrocarbons. Also the changes in hydrocarbon content in soil result in characteristic shifts of substrate utilisation patterns by the microorganisms, and the altered pattern of substrate utilisation corresponds to similar changes in abundance of hydrocarbons in the soils (Wunsche et al., 1995). This is not surprising, and in accordance with theories of gene accumulation and selection pressures we can predict a lower abundance of hydrocarbon degraders with depth, as selection pressure and favourable growth conditions in general decline with depth.

In this study, we investigated the hydrocarbon removal capacity and the microbial diversity of different soil layers after diesel contamination. The capacity of soil layers to remove hydrocarbons was evaluated (using simple microbial assays), while microbial diversity was evaluated from functional diversity (community-level physiological profiles using Biolog microplates) and genetic diversity (polymerase chain reaction-denaturing gradient gel electrophoresis, PCR-DGGE, of 16S rRNA).

\section{Materials and methods}

Soil: The contaminated soil layers were collected in sterile bags from a diesel-contaminated site at Coalsbrook, in the Free State Province, South Africa. The soil layers were collected 1 month after contamination by a leaking diesel pipeline. Direct push drilling to $2 \mathrm{~m}$ was used to sample the contaminated soil $(\mathrm{cs})$ layers at a depth of $1 \mathrm{~m}(\mathrm{cs} 1 \mathrm{~m})$ and $1.5 \mathrm{~m}(\mathrm{cs} 1.5 \mathrm{~m})$. The contaminated topsoil layer (cts) was collected within $10 \mathrm{~cm}$ of the surface of the soil. Uncontaminated topsoil (ucts) was also collected from the same site. Samples were kept at $41 \mathrm{C}$ until analysis, which was completed within $24 \mathrm{~h}$.

Microbiological analysis: To each of a series of 250-ml Erlenmeyer flasks containing $10 \mathrm{~g}$ soil, a $100 \mathrm{ml}$ portion of $0.2 \%$ tetra-sodium pyrophosphate was added, and the flasks were shaken orbitally $(140 \mathrm{rpm})$ for $45 \mathrm{~min}$. The mixtures were then allowed to settle for $5 \mathrm{~min}$ and serial dilutions prepared in physiological saline solution before inoculating agar and Biolog GN plates. Total recoverable heterotrophs (TRHs) were enumerated on nutrient agar (Biolab Diagnostics) spread plates. Hydrocarbon-degrading bacteria were isolated as described by Margesin and Schinner (1999a), with diesel being the only source of carbon and energy. Both types of agar plate were incubated in triplicate at $28 \mathrm{1C}$ and counted after $24 \mathrm{~h}$ and $7 \mathrm{~d}$, respectively.

Carbon source utilisation pattern determination: Sample dilutions were prepared as described above. Heterotrophic plate count data were used to adjust the samples to similar cell density for Gram-negative Biolog plate inoculation, and a 100-ul sample was added to each well. The Biolog plates were read at $600 \mathrm{~nm}$ using a Bio-Tek Elx800 microreader (Bio-Tek Instruments Inc.) before incubation at $28^{\circ} \mathrm{C}$, and again after 24,48 and $72 \mathrm{~h}$, all in triplicate. Statistical analyses 
were performed using STATISTICA for Windows release 5.1.

Respiration rate determination: The biological activity of the different samples was evaluated by monitoring oxygen consumption using a Micro-Oxymax Respirom-eter (Columbus Instruments). A 100-g sample of each soil layer was added to a $250-\mathrm{ml}$ bottle containing $10 \mathrm{ml}$ mineral salts medium without carbon or energy source. Nutrients were added to the soil layers to stimulate bioremediation in hydrocarbon-contaminated layers, treatments in which no nutrients were added serving as controls. $\mathrm{O}_{2}$ consumption was measured over 5 days. The composition of the nutrient solution was (gl medium): 10 $\mathrm{Na}_{2} \mathrm{HPO}_{4}, 10 \mathrm{KH} 2 \mathrm{PO} 4,2.5\left(\mathrm{NH}_{4}\right)_{2} \mathrm{SO}_{4}, 0.4 \mathrm{MgSO}_{4}, 0.05 \mathrm{CaCl}_{2}-2 \mathrm{H}_{2} \mathrm{O}, 0.0086$ EDTA, 0.01 FeS- $\mathrm{O}_{4}-7 \mathrm{H}_{2} \mathrm{O}, 0.004 \mathrm{ZnSO}_{4}-$ $7 \mathrm{H}_{2} \mathrm{O}, 0.01 \mathrm{MnSO}_{4} \mathrm{H}_{2} \mathrm{O}, 0.0015 \mathrm{CuSO}_{4}-5 \mathrm{H}_{2} \mathrm{O}, 0.0008 \mathrm{Co}\left(\mathrm{NO}_{3}\right)_{2} \bullet 6 \mathrm{H}_{2} \mathrm{O}$ and $0.0001\left(\mathrm{NH}_{4}\right)_{6} \mathrm{Mo}_{7} \mathrm{O}_{24} \cdot 4 \mathrm{H}_{2} \mathrm{O}$.

Chemical analysis: The contaminated soil layers were analysed in triplicate using the total petroleum hydrocarbons (TPH) method described in Margesin and Schinner (1999a) on $10 \mathrm{~g}$ samples.

DNA extraction and purification: Total DNA was isolated from the soil using the Bio 101 extraction kit (Bio Inc.)

PCR conditions: A 1-ul volume of extracted DNA was amplified by PCR with a 9600 thermal cycler (Perki-nElmer/Cetus). The PCR mixture used contained 100 um of each primer, $100 \mathrm{mM}$ of each deoxy-nucleo-side triphosphate, 5 ul 10 x PCR buffer, 0.25 ul hot start polymerase (5U/ul) (Perkin-Elmer, Roche Molecular Systems, Branchburg, NJ), 2.5 ul $2 \%$ bovine serum albumin and $40 \mathrm{ul}$ sterile water, to a final volume of $50 \mathrm{pl}$. The $16 \mathrm{~S}$ rRNA genes from soil microbial communities were amplified by PCR using the primers pA8f-GC (5'-CGC-CCG-CCG-CGC-GCG-GCG-GGC-GGG-GCGGGG-GCA-CGG-GGG-GAG-AGT-TTG-ATC-CTG-GCT-CAG-3') and KPRUN518r (5'ATTA CCGCGGCTGCTGG-3'), which have been found to be useful for 16S rRNA gene amplification in ecological and systematic studies (Øvreas and Torsvik, 1998). Samples were amplified as follows: $95^{\circ} \mathrm{C}$ for $10 \mathrm{~min}, 30$ cycles of denaturation $\left(1 \mathrm{~min}\right.$ at $\left.94{ }^{\circ} \mathrm{C}\right)$, annealing $\left(30 \mathrm{~s}\right.$ at $51^{\circ} \mathrm{C}$ ), extension $\left(1 \mathrm{~min}\right.$ at $\left.72{ }^{\circ} \mathrm{C}\right)$, and a final extension at $72{ }^{\circ} \mathrm{C}$ for $10 \mathrm{~min}$. Amplified DNA was examined by horizontal electrophoresis in $1 \%$ agarose with 5 -ul aliquots of PCR product.

DGGE: DGGE was performed using a Hoefer SE600 vertical dual cooler system (Hoefer Scientific, San Francisco, CA). PCR samples were loaded onto $8 \%(\mathrm{w} / \mathrm{v})$ polyacrylamide gels in $0.5 \mathbf{x}$ TAE (20mMTris, $10 \mathrm{mMacetate}, 0.5 \mathrm{mMNa}$-EDTA, pH 7.4). The polyacrylamide gels (bisacrylamide gel stock solution, 37.55:1; BioRad Laboratories) were prepared with a 20$55 \%$ gradient of denaturant (urea and formamide) and allowed to polymerise. Electrophoresis was run at $60{ }^{\circ} \mathrm{C}$, first for 10 min at $20 \mathrm{~V}$ and then overnight at $70 \mathrm{~V}$. After electrophoresis, the gels were stained for $15 \mathrm{~min}$ in SYBR Green I nucleic acid gel stain, rinsed in distilled water for $1 \mathrm{~min}$ and photographed with a Polaroid MP4 Land camera. The gels were analysed using a software program developed by Svein Norland (Department of Microbiology, University of Bergen), where the presence/absence of bands was recorded. Clustering was based on the simple matching algorithm, while the dendrogram was drawn applying the group average method.

\subsection{Diversity indices}

The Shannon index, If (Shannon, 1948), was calculated $(\log 2)$ on the basis of biotypes defined in the cluster analysis on data retrieved from PCR-DGGE. The equitability / index (Pielou, 1966) was also calculated (Watve and Gangal, 1996).

\section{Results}

\subsection{Microbiological analysis}

The number of TRHs decreased with soil depth (Fig. 1). Similar results were obtained for the hydro-carbon-degrading bacteria. There was little difference in the number of TRHs and hydrocarbon-degrading bacteria in the cs $1 \mathrm{~m}$ and $\operatorname{cs} 1.5 \mathrm{~m}$ samples.

The TPH concentration was highest in the cs $1.5 \mathrm{~m}$ layer, followed by the cts and then the cs $1 \mathrm{~m}$ layer (Fig. 2). However, TPH removal during the period of incubation reflected the difference in the number of bacteria in the samples, as it was higher in the topsoil than in the other soil layers.

There was no significant difference between TPH removal in the nutrient-amended treatments and the controls in the cs $1 \mathrm{~m}$ and cs $1.5 \mathrm{~m}$ layers (Fig. 2). Removal efficiency was $48 \%$ in the cts, compared with $31 \%$ and $11 \%$, respectively, in the cs 1.5 and cs $1 \mathrm{~m}$ layers. Soil layers with large numbers of recoverable hydrocarbon degrading bacteria had greater removal capacity than soil layers with low counts of such bacteria.

\subsection{Respiration rate determination}

The respiration rate reflected the difference in the number of bacteria in each soil layer and the availability of nutrients. The cts had the highest $\mathrm{O}_{2}$ consumption rate (Fig. 3a). Where nutrients were added to the contaminated soil to stimulate the biological removal of hydrocarbons (Churchill et al., 1995; Braddock et al., 1997; Seklemova et al., 2001), the rate was also higher in the amended treatments than in unamended controls (Fig 3a, b). The respiration rate in ucts was low compared with 


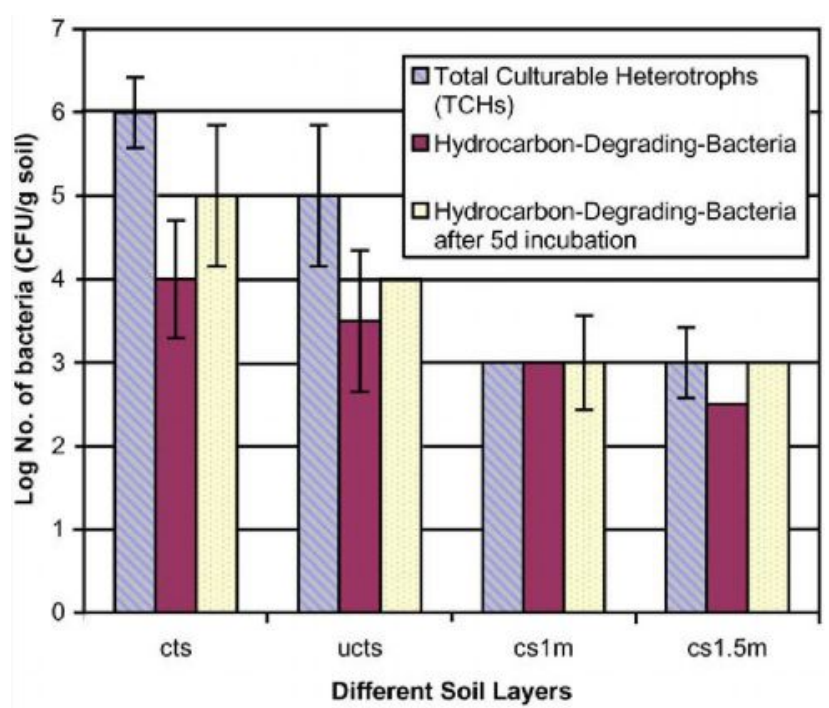

Fig. 1. Bacterial counts for different soil layers at a Coalsbrook dieselcontaminated site. Key: cts-contaminated topsoil; ucts-uncontami-nated topsoil; cs1m-contaminated soil at $1 \mathrm{~m}$; cs $1.5 \mathrm{~m}$-contaminated soil at 1.5 $\mathrm{m}$.

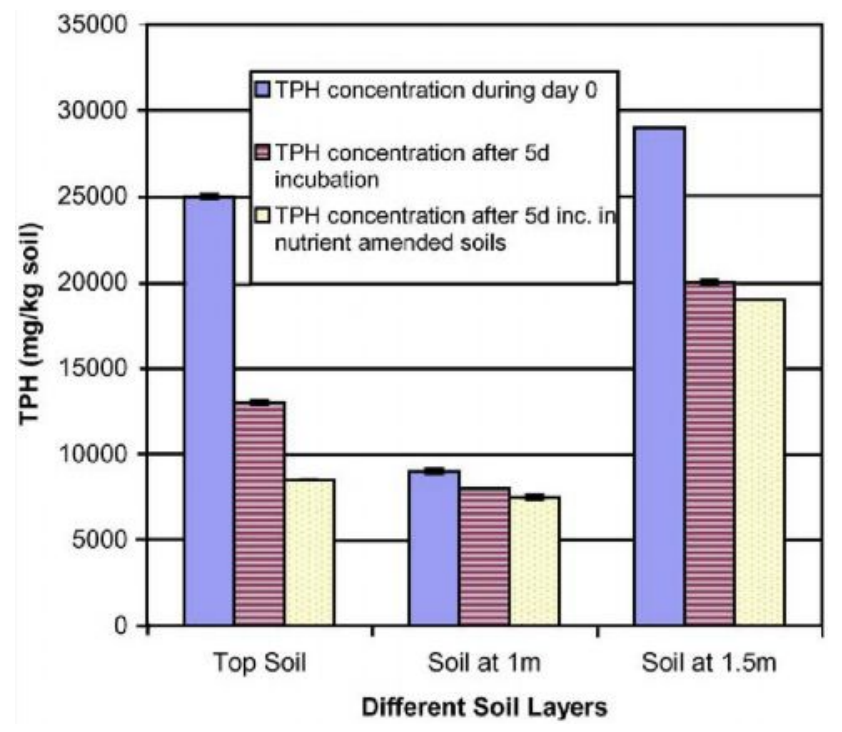

Fig. 2. Concentration of hydrocarbons in different soil layers at Coalsbrook.

\subsection{Biolog analysis}

Principal component analysis (PCA) of the colour response data of the soil layers revealed different substrate utilisation patterns (Fig. 4).

PCA was performed to characterise the associations between samples, taking into account the absorbance values for all 96-response wells at different times of incubation. Two principal factors were isolated from the individual ucts, cts, cs $1 \mathrm{~m}$ and cs $1.5 \mathrm{~m}$ patterns that explained $58 \%$ of the variation. This low percentage variation, explained by the two factors, could be a result of the small number of samples used in the analysis. The use of more samples would probably improve the variation explained by the two factors. For the four samples, factor 1 was related to the absorbance values for the wells, while factor 2 was related to the incubation time.

The relationship between the substrate utilisation patterns was further analysed using hierarchical clustering. In a dendrogram (Fig. 5), the results of cluster analysis also showed that the metabolic activities of cs $1 \mathrm{~m}$ were more 'closely' related to cs $1.5 \mathrm{~m}$ than to ucts and cts. The uncontaminated and contaminated soils differed in this respect.

Both the dendrogram and the PCA illustrate that the substrate utilisation pattern of the microbial communities in different soil layers differ.

\subsection{Polymerase chain reaction-denaturing gradient gel electrophoresis}

DGGE profiles of amplified 16S rDNA fragments from DNA extracted from the soil bacterial fractions revealed differences in the DNA fingerprint for the different soil layers. The profiles of the contaminated and uncontaminated samples were different (Fig. 6), with the profile of the cs $1.5 \mathrm{~m}$ being difficult to resolve.

Cluster analysis using a dendrogram revealed that $\operatorname{cs} 1 \mathrm{~m}$ was more closely related to cts than to ucts. The Shannon diversity index $\left(\mathrm{H}^{0}\right)$ revealed a higher diversity in topsoil compared with other soil layers (Table 1). The equitability $\left(\mathrm{J}^{0}\right)$ of all populations ranged from 0.73 to 0.95 . 


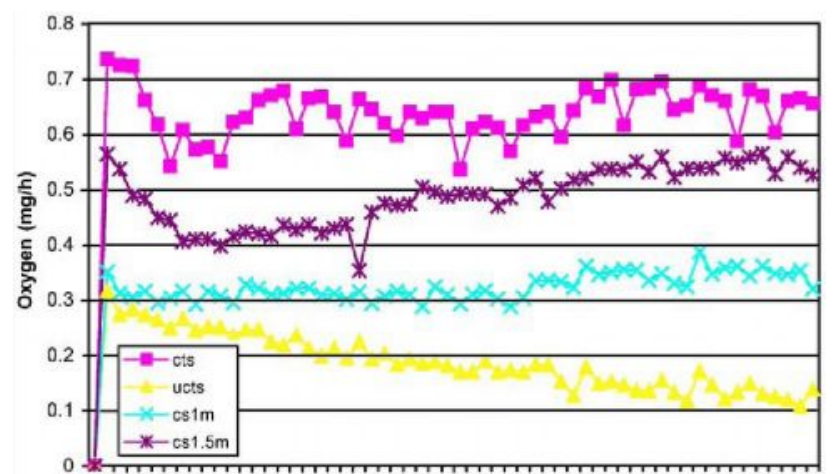

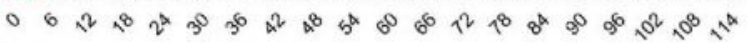

(a)

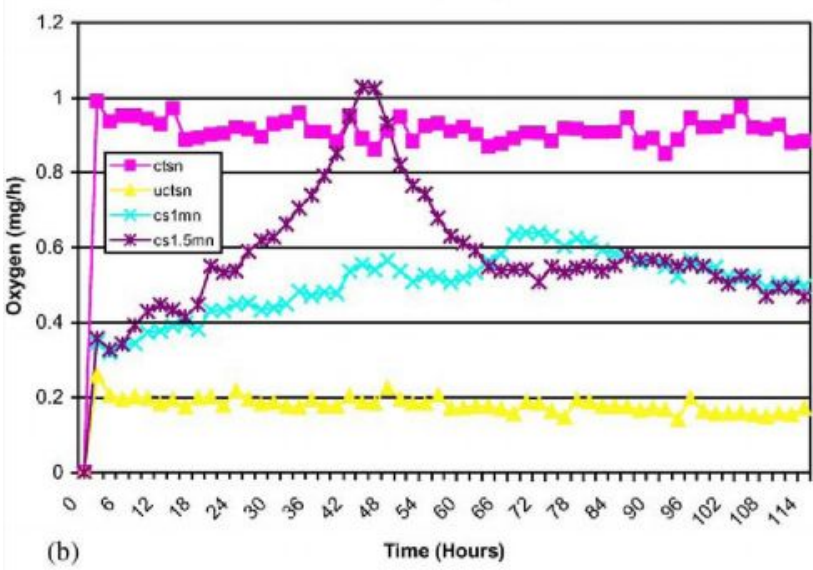

Fig. 3. Oxygen consumption by microorganisms in different layers of diesel-contaminated soil: (a) soil without added nutrients; (b) soil with added nutrients. Key: cts-contaminated topsoil, no nutrients added; ctsncontaminated topsoil, nutrients added; ucts-uncontaminated topsoil, no

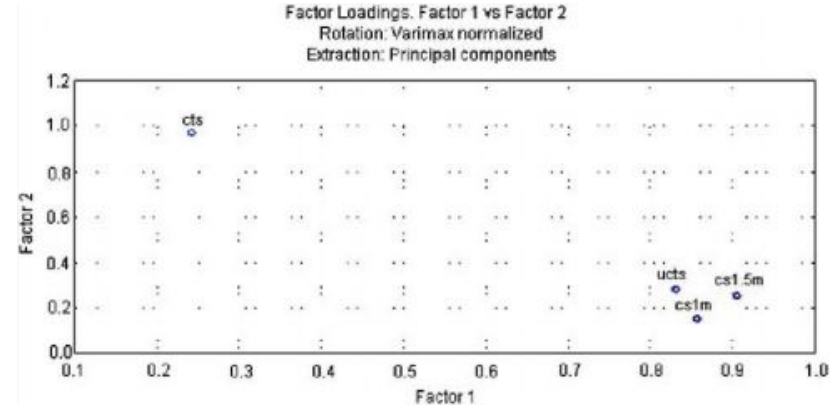

Fig. 4. Substrate utilisation pattern of soil layers as indicated by PCA. Key: as Fig. 1.

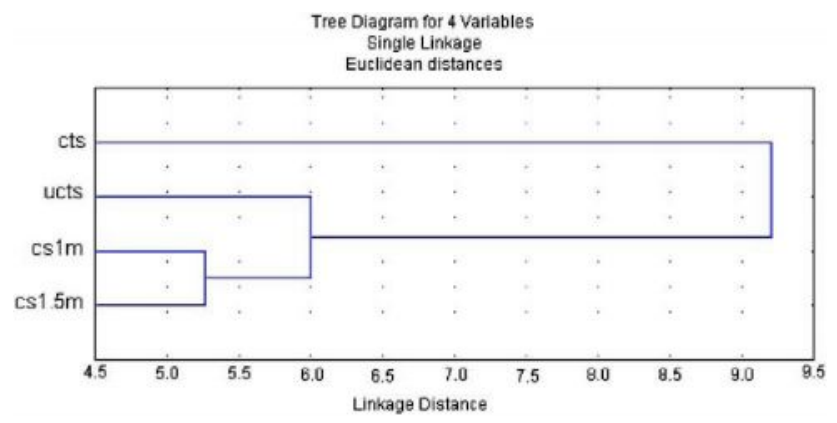

Fig. 5. Cluster analysis of different soil layers.

nutrients added; uctsn-uncontaminated topsoil, nutrients added; cs1mcontaminated soil at $1 \mathrm{~m}$, no nutrients added; cs1mn-contaminated soil at $1 \mathrm{~m}$, nutrients added; cs $1.5 \mathrm{~m}$-contami-nated soil at $1.5 \mathrm{~m}$, no nutrients added; cs $1.5 \mathrm{mn}-$ contaminated soil at $1.5 \mathrm{~m}$, nutrients added.
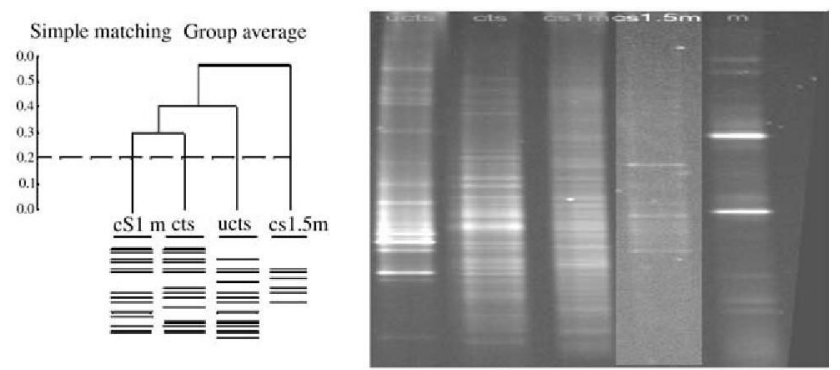

Fig. 6. (a) Cluster analysis of microbial communities at different soil layers and (b) DGGE fingerprints. Key: ucts-uncontaminated topsoil; ctscontaminated topsoil; cs $1 \mathrm{~m}$ - contaminated soil layer at $1 \mathrm{~m}$; cs $1.5 \mathrm{~m}$-contaminated soil layer at $1.5 \mathrm{~m}$; m-marker. Lines beneath codes in (a) represent the bands detected.

Indices

Table 1 Diversity

ucts cts

cs $1 \mathrm{~m}$

cs $1.5 \mathrm{~m}$

\section{Soil type}

2.120667

0.826787

2.52069

0.909147

1.981935
0.731868 


\section{Discussion and conclusion}

In this study, the number of TRHs and hydrocarbon-degrading bacteria decreased with soil depth. This can be attributed to nutrient and oxygen limitations to the biota of the soil subsurface. According to Zhou et al. (2002), spatial and resource factors influence microbial diversity in soil. Similar results were obtained with the hydrocarbon degrading bacteria after incubation for five days. However, there was little difference in the number of TRHs and hydrocarbon degrading bacteria in the 1-and 1.5-m samples, possibly owing largely to similarities of nutrient levels in the soil layers.

The high concentration of hydrocarbons at a depth of $1.5 \mathrm{~m}$ (Fig. 2) indicates the potential mobility of the pollutants to deeper soil layers. The removal of TPH reflected the number of bacteria in each soil layer, with removal being $48 \%$ in cts compared with $31 \%$ in cs $1.5 \mathrm{~m}$ and $11 \%$ in cs $1 \mathrm{~m}$. Owing to the proximity of the $1.5 \mathrm{~m}$ layer to ground water at a depth of 2 $\mathrm{m}$, microbial activity could consequently be higher at $1.5 \mathrm{~m}$ than at $1 \mathrm{~m}$.

Since it is well known that different soil layers harbour different numbers of bacteria, it was expected that the soil layers would have a different pattern of substrate utilisation, especially as both PCA and cluster analysis revealed differences between the soil layers. The closer relationship of $\operatorname{cs} 1 \mathrm{~m}$ to $\operatorname{cs} 1.5 \mathrm{~m}$ than to ucts and cts (Fig. 5) can be attributed to the similarities in nutritional (organic matter, limiting nutrients) and environmental conditions ( $\mathrm{pH}$, temperature) of these 2 soil layers, but the closeness was not evident when clustering the DGGE profiles of the 16S rDNA fragments (Fig. 6).

The difference between ucts and cts evident in both substrate utilisation patterns and DGGE (Figs. 4 and 6) can be attributed to the changes in the composition of microbial populations brought about by changes in hydrocarbon content (Atlas et al., 1991; Wunsche et al., 1995). The higher diversity in the topsoil indicated by the Shannon diversity index (Table 1) can be ascribed to the relatively large amount of nutrients (organic matter and possibly limiting nutrients) in the topsoil than in the other soil layers. The diversity indices corroborated the observations on functional diversity; the high removal capacity of the topsoil can be attributed to a greater number of bacteria able to degrade the hydrocarbons.

As indicated earlier, the DGGE profiles of amplified 16S rDNA fragments for cs $1.5 \mathrm{~m}$ were difficult to resolve, however, the bands detected by the software program revealed few fragments relative to the other soil layers. The use of Archae primers instead of bacterial primers may enhance the chance of revealing the differences between the DGGE profiles of the different soil layers (Øvreas and Torsvik, 1998). The data on the functional and genetic diversity revealed that these two approaches to studying microbial diversity can complement each other, since the community-level physiological profiles (CLPP) measured the metabolic activities of different environmental samples while the PCR-DGGE provides information about the microbial structure. The data on CLPP and PCR-DGGE suggest that in combining the functional and genetic approaches there is the potential to provide a clear picture about the abundance of a variety of species in an ecosystem. Further studies are required in order to understand the effect of not only other pollutants but also the influence of soil components (pore volume, level of adsorbents and other environmental factors) on microbial diversity of different soil layers in both 'shallow' and deep aquifers. The results suggest that in hydrocarbon contaminated soil biological removal of hydrocarbons differs with soil layer, and also that the microbial diversity (as measured by CLPP and PCR-DGGE) varies with depth. Information about metabolic activities of different soil layers is critical when assessing the footprints of degradation processes during monitored natural attenuation (Smets et al., 2002).

\section{References}

Atlas, R.M., 1981. Microbial degradation of petroleum hydrocarbons: an environmental perspective. Microbiological Reviews 45, 180-209.

Atlas, R.M., Horowitz, A., Krichevsky, M., Bej, A.K., 1991. Response of microbial populations to environmental disturbance. Microbial Ecology 22, 249256.

Balkwill, D.L., Fredrickson, J.K., Thomas, J.M., 1989. Vertical and horizontal variation in the physiological diversity of the aerobic chemoautotrophic bacterial microflora in the deep southeast coastal plain subsurface sediments. Applied and Environmental Microbiology 55, $1058-1065$.

Balkwill, D.L., Ghiorse, W.C., 1985. Characterisation of subsurface bacteria associated with two shallow acquifers in Oklahoma. Applied and Environmental Microbiology 50, 580-588.

Bone, T.L., Balkwill, D.L., 1988. Morphological and cultural comparison of microorganisms in surface soil and subsurface sediments at a pristine study sites in Oklahoma. Microbial Ecology 16, 49-64.

Braddock, J., Ruth, M., Catteral, P., Walworth, J., Mcarthy, K., 1997. Enhancement and inhibition of microbial activity in hydrocarbon contaminated aerctic soils: implications for nutrient amended bioremediation. Environmental Science and Technology 31, 2078-2084.

Bundy, J.G., Paton, G.I., Campell, C.D., 2002. Microbial communities in different soil types do not converge after diesel contamination. Journal of Applied Microbiology 92, 276-288.

Churchill, S.A., Griffin, R.A., Jones, L.P., Churchill, P.F., 1995. Biodegradation rate enhancement of hydrocarbons by an oleophilic fertilizers and rhamnolipid biosurfactant. Journal of Environmental Quality 24, 19-28.

Ghiorse, W.C., Balkwill, D.L., 1983. Enumeration and morphological characterisation of bacteria indigenous to subsurface environments. Developments in Industrial Microbiology 24, 213-224.

Ghiorse, W.C., Wilson, J.T., 1988. Microbial ecology of the terrestrial subsurface. Advances in Applied Microbiology 33, 107-172.

Juck, D., Charles, T., Whyte, L.G., Greer, C.W., 2000. Polyphasic microbial community analysis of petroleum hydrocarbon-contaminated soils from two northern Canadian communities. FEMS Microbiology Ecology 33, 241-249.

Krumholz, L.R., 1998. Microbial ecosystems in the earth's subsurface. American Society for Microbiology News 64, 197-202.

Leahy, J.G., Colwell, R.R., 1990. Microbial degradation of hydrocarbons in the environment. Microbiological Reviews 54, $305-315$.

Lindstrom, J.E., Barry, R.P., Braddock, J.F., 1999. Long-term effects on microbial communities after a subarctic oil spill. Soil Biology and Biochemistry 
$31,1677-1689$.

MacNaughton, S.J., Stephen, J.R., Venosa, A.D., Davis, G.A., Chang, Y.J., White, D.C., 1999. Microbial population changes during bioremediation of an experimental oil spill. Applied and Environmental Microbiology 65, 3566-3574.

Margesin, R., Schinner, F., 1999a. World Journal of Microbiology and Biotechnology 15, in press.

Øvreas, L., Torsvik, V., 1998. Microbial diversity and community structure in two different agricultural soil communities. Microbial Ecology 36, 303-315.

Pielou, EC., 1966. The measurement of diversity in different types of biological collections. Journal of Theoretical Biology 13, 131-144.

Seklemova, E., Pavlova, A., Kovacheva, K., 2001. Biostimulation- based bioremediation of diesel fuel: field demonstration. Biodegradation 12, 311-316.

Shannon, C.E., 1948. A mathematical theory of communication. Bell System Technical Journal 27, 379-423.

Smets, B.F., Siciliano, S.D., Verstraete, W., 2002. Natural attenuation, extant microbial activity forever and ever? Environmental Microbiology 4, 315-317.

Stephen, J.R., Chang, Y.J., Gan, Y.D., Peacock, A., Pfiffner, S.M., Barcelona, M.J., White, D.C., MacNaughton, S.J., 1999. Microbial characterisation of a JP-4 fuel contaminated site using a combined lipid biomarker/polymerase chain reaction-denaturing gradient gel electrophoresis (PCR-DGGE)-based approach. Environmental Microbiology 1, 231-241.

Watve, M.G., Gangal, R.M., 1996. Problems in measuring bacterial diversity and a possible solution. Applied and Environmental Microbiology 62, 42994301.

Wunsche, L., Bruggemann, L., Babel, W., 1995. Determination of substrate utilisation patterns of soil microbial communities: an approach to assess population changes after hydrocarbon pollution. FEMS Microbiology Ecology 17, 295-306.

Zhou, J., Xia, B., Treves, D.S., Wu, L.Y., Marsh, T.L., O’Neill, R.V., Palumbo, A.V., Tiedje, J.M., 2002. Spatial and resources factors influencing high microbial diversity in soil. Applied and Environmental Microbiology 68, 326-334. 